\title{
A Simple Inelastic Constitutive Model for Evaluation of Stable Cyclic Stress Response under Nonproportional Straining
}

\author{
Takamoto ITOH ${ }^{\star}$, Masao SAKANE $^{\star *}$ and Xu CHEN ${ }^{\star \star *}$
}

(Received February 20, 2002)

This paper proposes a simple two-surface model for cyclic incremental plasticity based on combined Mroz and Ziegler kinematic hardening rules under nonproportional loading. The model has only seven material constants and a nonproportional factor which describes the degree of additional hardening. Cyclic loading experiments with fourteen strain paths were conducted using Type 304 stainless steel. The simulation has shown that the model was precise enough to calculate the stable cyclic stress-strain relationship under nonproportional loadings.

Key Words : Inelastic Constitutive Equation, Stress and Strain Relationship, Low Cycle Fatigue, Nonproportional Loading

\section{Nomenclature}

E Young's modulus for elasticity

G Shear modulus

c Strain hardening modulus

n Cyclic hardening exponent

$\mathrm{K} \quad$ Cyclic hardening coefficient

$\mathrm{K}_{\mathrm{NP}} \quad$ Nonproportional cyclic hardening coefficient

$\mathrm{C}_{\mathrm{s}} \quad$ Material constant

$\alpha \quad$ Material constant for additional hardening

$\mathrm{f}_{\mathrm{NP}} \quad$ Nonproportional factor

$\varepsilon, \gamma \quad$ Axial and shear strains, respectively

$\mathrm{F} \quad$ Function of yield surface

$F^{*} \quad$ Function of limit surface

$R \quad$ Radius of yield surface

$\mathrm{R}^{*} \quad$ Radius of limit surface

$\mathrm{X}_{\max } \quad$ Maximum back stress

$\sigma_{1}, \sigma_{3}$ Effective axial and shear stresses, respectively

$\varepsilon_{1}, \varepsilon_{3} \quad$ Effective axial and shear strains, respectively

$\boldsymbol{n}_{1}, \boldsymbol{n}_{3}$ Orthogonal vectors in the stress space

$\boldsymbol{X} \quad$ Vector pointing the center of yield surface

$\sigma \quad$ Stress vector

$\sigma^{*} \quad$ Stress vector on the limit surface

* Dept. of Mechanical Engineering

** Dept. of Mechanical Engineering, Ritsumeikan Univ.

"** Dept. of Chemical Engineering Machinery, Tianjin Univ. $\varepsilon \quad$ Strain vector

$d \varepsilon^{P} \quad$ Vector of plastic strain increment

\section{Introduction}

Many practical components such as pressure vessels and turbine blades receive nonproportional damage under the combination of thermal and mechanical loadings. Nonproportional cyclic loading causes more damage than proportional loading and occasionally reduces low cycle fatigue life. Type 304 stainless steel is known as a typical material which shows significant additional cyclic hardening under nonproportional loading ${ }^{[1]-[3]}$. Low cycle fatigue lives under nonproportional loading were drastically reduced by the additional hardening depending on strain history. The maximum reduction in life occurred by a factor of 10 compared with the proportional straining ${ }^{[3],[4]}$. On the other hand, aluminum alloys which showed a small additional hardening under nonproportional loading ${ }^{[2],[3],[5]-[8]}$ gave a small reduction in life $\mathrm{e}^{[2],[3],[8]}$. The amount of additional hardening also depends on material. Thus, the reduction in low cycle fatigue life has a close connection with the additional hardening depending on both loading history and material. Development of an accurate and convenient inelastic constitutive equation has been needed for the quantitative estimates of additional hardening.

Studies of plasticity have made great progress in these two decades to express the cyclic deformation under 
complex multiaxial loadings. Many inelastic constitutive equations were proposed for complex multiaxial loading ${ }^{[9]-[17]}$ using a relatively large number of material constants. The two-surface model has been recently receiving attention since it provides the reasonable prediction for nonproportional cyclic stress-strain response $^{[10],[13],[18]-[22]}$. The one of the authors ${ }^{[23]}$ also proposed the two-surface model superposing Mroz and Ziegler kinematic hardening rules to simulate the mechanical ratchetting and the nonproportional cyclic deformation of 2014 aluminum alloy. These many inelastic constitutive models insist the validity of predicting the amount of additional hardening by comparing with a limited number of experimental results. However, there are many factors which influence the amount of additional hardening ${ }^{[3],[8]}$, like phase shift, rotation and change of principal strain direction, step length etc., so that the validity of constitutive model must be demonstrated by comparing the model analysis with the nonproportional results including these factors. In this meaning, there is no well demonstrated inelastic constitutive model for additional hardening prediction.

The objective of this paper is to present an inelastic constitutive model that can predict the stable cyclic nonproportional stress response. The inelastic constitutive model proposed by Chen et al. ${ }^{[23]}$ was improved by introducing the material parameter which expresses the material dependence of additional hardening and by the nonproportional factor which expresses the severity of nonproportional loading. The inelastic constitutive model was applied to the extensive nonproportional data under 14 types of strain paths and the applicability of the model was discussed.

\section{Experimental Procedure and Nonproportional Straining}

The material tested was Type 304 stainless steel which received a solution treatment at $1373 \mathrm{~K}$ for one hour. Shape and dimensions of the specimen was a thin-walled tube with $12 \mathrm{~mm}$ O.D., $9 \mathrm{~mm}$ I.D. and $4.6 \mathrm{~mm}$ gage length as shown in Fig.1. The test apparatus was a tension-torsion servo-controlled electric-hydraulic machine. Axial and shear strains were measured on the specimen surface by a tension-torsion extensometer.

Multiaxial cyclic loading tests were carried out using 14 types of proportional and nonproportional strain histories at room temperature. Figure 2 shows the 14 strain histories, where $\varepsilon$ and $\gamma$ are the axial and shear strains, respectively, and alphabets attached indicate representative points along the strain path which will be referred in the later discussion. Case 0 is a push-pull test which is the basic test for predicting the nonproportional cyclic stress and strain response. Strain paths shown in the figure were determined so as to make clear the various effects in nonproportional straining. In strain paths $1-13$, the total axial strain range, $\Delta \varepsilon$, had the same strain magnitude as the total shear strain range, $\Delta \gamma$, on Mises' equivalent basis. Two total strain ranges were employed in all the tests except Case 0 . They

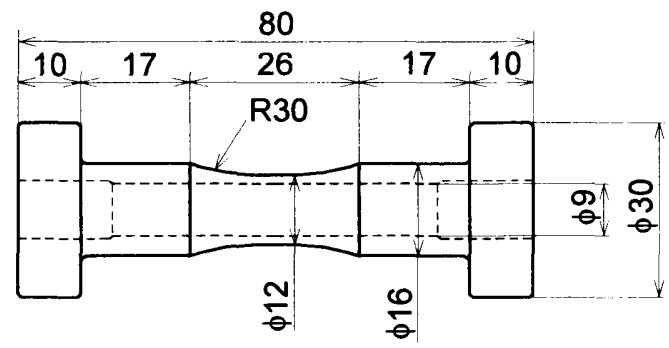

Fig.1 Shape and dimensions of the specimen tested (mm)
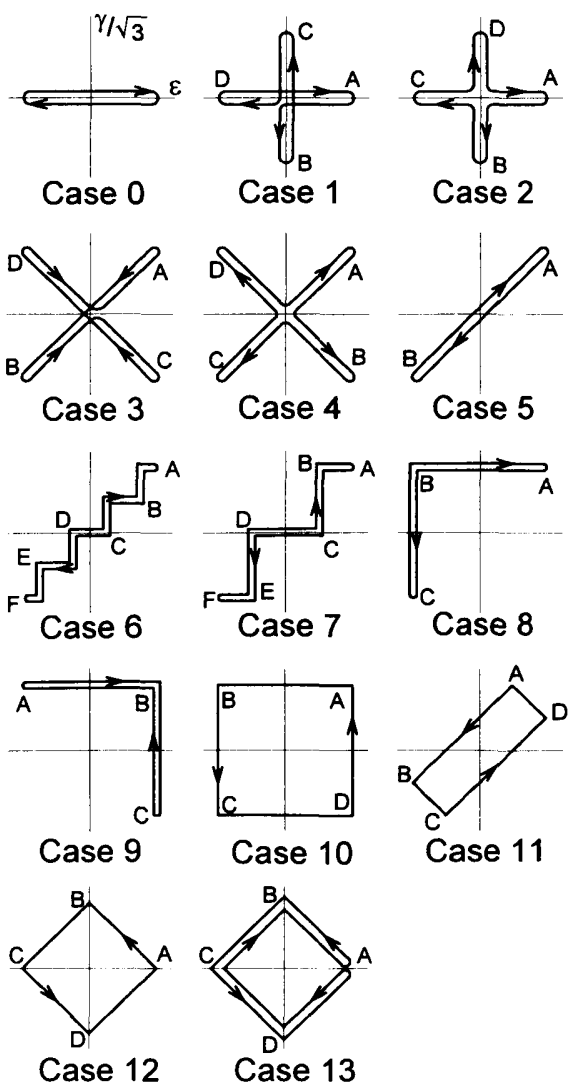

Fig.2 Proportional and nonproportional strain paths 
were $\Delta \varepsilon=0.5 \%$ and $0.8 \%$. In Case 0 , the total strain range was varied from $0.5 \%$ to $1.5 \%$. The strain rate was $0.1 \% / \mathrm{sec}$ on Mises' equivalent base. A detailed description of the test procedure was presented in the previous paper ${ }^{[3]}$ together with the nonproportional low cycle fatigue lives.

\section{Nonproportional Low Cycle Fatigue Strain Parame-} ter

Nonproportional loading drastically reduces the low cycle fatigue life accompanied with additional hardening $^{[1]-[3],[8]}$. The reduction in fatigue life is closely related to the additional hardening under nonproportional loading, depending on the loading history and material $^{[3],[8]}$. The authors proposed the nonproportional strain parameter for predicting the low cycle fatigue lives of Type 304 stainless steel and 6061 aluminum alloy. The proposed parameter is expressed as ${ }^{[3],[8]}$

$$
\Delta \varepsilon_{\mathrm{NP}}=\left(1+\alpha \mathrm{f}_{\mathrm{NP}}\right) \Delta \varepsilon_{\mathrm{I}}
$$

where $\Delta \varepsilon_{\mathrm{I}}$ is the maximum principle strain range under nonproportional straining, $\alpha$ the material constant which discriminates the material dependency of additional hardening and $\mathrm{f}_{\mathrm{NP}}$ the nonproportional factor which expresses the severity of nonproportional loading.

The value of $\alpha$ is defined as the ratio of stress amplitude under 90 degree out-of-phase loading (circular strain path in $\gamma / \sqrt{3}-\varepsilon$ plot) to that under proportional loading. The 90 degree out-of-phase loading shows the maximum additional hardening among all the nonproportional histories $^{[3],[4]}$. For Type 304 stainless steel, the stress amplitude under 90 degree out-of-phase loading was increased up to $90 \%$ in comparison with the proportional loading, so the value of $\alpha$ takes 0.9 .

The nonproportional factor which accounts for the severity of nonproportional strain is calculated from strain history and is defined as

$$
f_{N P}=\frac{\pi}{2 T \varepsilon_{I \max }} \int_{b}^{T}\left(|\sin \xi(t)| \varepsilon_{I}(t)\right) d t
$$

Table 1 Values of nonproportional factor

\begin{tabular}{c|c|c|c|c|c|c|c}
\hline Case & 0 & 1 & 2 & 3 & 4 & 5 & 6 \\
\hline $\mathrm{f}_{\mathrm{NP}}$ & 0 & 0.34 & 0.34 & 0.39 & 0.39 & 0 & 0.10 \\
\hline Case & 7 & 8 & 9 & 10 & 11 & 12 & 13 \\
\hline $\mathrm{f}_{\mathrm{NP}}$ & 0.20 & 0.77 & 0.77 & 0.77 & 0.46 & 0.77 & 0.77 \\
\hline
\end{tabular}

where $\varepsilon_{I}(t)$ and $\xi(t)$ are the absolute value of maximum principal strain and the angle of maximum principal strain direction at time $t$, respectively. The former parameter shows the strain amplitude and the latter the principal strain direction change under nonproportional loading. In the equation, $T$ and $\varepsilon_{\operatorname{lmax}}$ are the time for a cycle and the maximum value of $\varepsilon_{\mathrm{I}}(\mathrm{t})$ in a cycle. Detailed description of the nonproportional low cycle fatigue parameter in equation (1) is omitted here and the reader is referred to the previous paper $^{[3]}$ for details. The values of $f_{N P}$ for each case are listed in Table 1 .

The reason for making $f_{\mathrm{NP}}$ an integral form is that the experimental results indicated that nonproportional low cycle fatigue lives are significantly influenced by the degree of principal strain direction change and strain length after the direction change. The value of $f_{N P}$ takes zero under proportional straining such as Case 0 and 5 in which no change of principal strain direction is occurred. $f_{N P}$ takes the maximum value of unity under the 90 degree out-of-phase straining which has the continuous change of principal strain direction with the constant equivalent strain corresponding to $\varepsilon_{\text {Imax }}$, which results in the largest additional hardening and the largest reduction in the low cycle fatigue life ${ }^{[3],[4]}$. However, when a material has a small value of $\alpha$, a small additional hardening and a small reduction in fatigue life are occurred even though the value of $f_{N P}$ is large ${ }^{[8]}$. Therefore, reduction in nonproportional low cycle fatigue is connected with the degree of additional hardening ${ }^{[3]}$ depending on both the loading history and materials. The material dependency of the additional hardening can be explained by the mechanism of slip systems.

In nonproportional loading, the principal strain direction is changed with proceeding cycles, so the maximum shear stress plane is changed continuously in a cycle. This causes an interaction between slip systems and which results in the formation of small cells ${ }^{[2],[6],[7],[24]}$ for Type 304 steel. Large additional hardening was occurred by the interaction of slip systems for that steel because of low stacking fault energy. 6061 aluminum alloy, on the other hand, is a material of high stacking fault energy and slips of dislocations are wavy. No large interaction occurred in 6061 aluminum alloy since dislocations change their glide planes easily following the variation of the maximum principal strain direction $^{[6],[7],[24]}$

The term, $\left(1+\alpha f_{N P}\right)$, in equation (1) reflects the intensity of the interaction between slip systems which 
depends on both the material and strain history ${ }^{[24]}$. The equivalent strain including $\left(1+\alpha f_{N P}\right)$ in equation (1) gave a satisfactory correlation of fatigue lives under nonproportional straining, and predicted the additional hardening due to nonproportional loading ${ }^{[3],[8]}$. Therefore, it is considered that the term of $\left(1+\alpha f_{N P}\right)$ becomes a good parameter to evaluate the effect of loading history and of material dependency on stress-strain relationship under complex nonproportional loadings. In the following, the inelastic constitutive equation which includes $(1+\alpha$ $\mathrm{f}_{\mathrm{NP}}$ ) is developed.

\section{Two-surface Plasticity Model Based on Kinematic Hardening Rule}

When a thin-walled tube specimen is subjected to combined axial and torsional loading, the stress and strain state is expressed in terms of deviatoric vector planes. The definition of the axial-torsional subspace follows as an Ilyushin's five-dimensional deviatoric vector subspace and a stress vector is defines as

$$
\boldsymbol{\sigma}=\sigma_{1} n_{1}+\sigma_{3} n_{3}
$$

In this equation, $\sigma_{1}$ and $\sigma_{3}$ are the effective axial and shear stresses, respectively. Based on the Mises' equivalent value $\sigma, \sigma_{1}$ and $\sigma_{3}$ can be given by $\sigma$ and $\sqrt{3} \tau$, where $\sigma$ and $\tau$ are the axial and torsional shear stresses, respectively. $\quad \boldsymbol{n}_{1}$ and $\boldsymbol{n}_{3}$ are the orthogonal base vectors in the stress space.

The strain vector is defined as

$$
\varepsilon=\varepsilon_{1} n_{1}+\varepsilon_{3} n_{3}
$$

Similarly, $\varepsilon_{1}$ is equal to the axial strain and $\varepsilon_{3}$ is equal to the shear strain $\gamma / \sqrt{3}$.

Mises' equivalent stress and strain are expressed by the following equations using $\sigma_{1}, \sigma_{3}, \varepsilon_{1}$ and $\varepsilon_{3}$.

$$
\begin{aligned}
& \sigma_{\mathrm{e}}=\sqrt{\sigma_{1}{ }^{2}+{\sigma_{3}}^{2}} \\
& \varepsilon_{\mathrm{e}}=\sqrt{\varepsilon_{1}{ }^{2}+\varepsilon_{3}{ }^{2}}
\end{aligned}
$$

The total strain increment, $\mathrm{d} \varepsilon$, is assumed to be decomposed into the elastic and plastic strain increments, $d \varepsilon^{e}$ and $\mathrm{d} \varepsilon^{\mathrm{p}}$.

$$
\mathrm{d} \varepsilon=\mathrm{d} \varepsilon^{\mathrm{e}}+\mathrm{d} \varepsilon^{\mathrm{p}}
$$

where the elastic strain components are given by

$$
\mathrm{d} \varepsilon_{1}^{\mathrm{e}}=\frac{\mathrm{d} \sigma_{1}}{\mathrm{E}}, \mathrm{d} \varepsilon_{3}^{\mathrm{e}}=\frac{\mathrm{d} \sigma_{3}}{3 \mathrm{G}}
$$

$\mathrm{E}$ and $\mathrm{G}$ are Young's and shear moduli, respectively.

Classical plasticity theory is based on the concept of the yield surface. The movement of the yield surface under cyclic loading is described by the kinematic hardening rule and the dimensional change of the yield surface is described by the isotropic hardening rule. Mises' yield surface is expressed in the stress space as

$$
\mathrm{F}=(\sigma-X) \cdot(\sigma-X)-\mathrm{R}^{2}=0
$$

where $\boldsymbol{X}$ is a vector indicating the center of yield surface and $R$ is a radius of yield surface.

The limit surface, $\mathrm{F}^{*}$, in the stress space is required in the two-surface model which is given as,

$$
\mathrm{F}^{*}=\sigma^{*} \cdot \sigma^{*}-\left(\mathrm{R}^{*}\right)^{2}=0
$$

where $\sigma^{*}$ is a limit stress vector and $\mathrm{R}^{*}$ is the radius of limit surface equated with the radius of yield surface and the maximum back stress, $X_{\max }$.

$$
\mathrm{R}^{*}=\left|\mathrm{X}_{\max }\right|+\mathrm{R}
$$

In order to describe the Bauschinger effect, a simple kinematic hardening rule was proposed by Ziegler ${ }^{[25]}$ given by the next equation:

$$
\mathrm{d} X=\mathrm{d} \mu_{\mathrm{Z}}(\sigma-X)
$$

On the other hand, $\mathrm{Mroz}^{[26]}$ proposed a kinematic hardening rule based on the concept of the nested yield

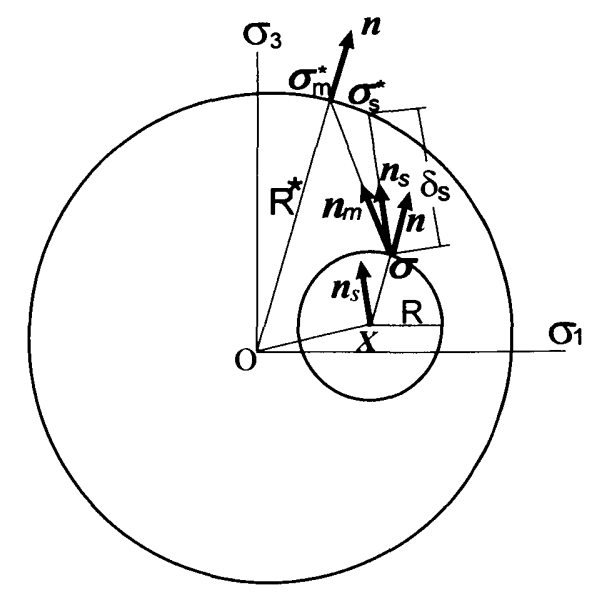

Fig.3 Two-surface model for superposing the two kinematic hardening rules 
and the loading surface,

$$
\mathrm{d} X=\mathrm{d} \mu_{\mathrm{m}}\left(\sigma_{\mathrm{m}}^{*}-\sigma\right)
$$

For the two-surface model, $\sigma_{\mathrm{m}}{ }^{*}$ is the stress vector on the limit surface which has the same direction as the normal vector, $\boldsymbol{n}$, at the stressing point, $\boldsymbol{\sigma}$, on the yield surface, i.e., $\sigma_{\mathrm{m}}{ }^{*}$ and $\sigma$ are located at similar points on the yield and limit surfaces, respectively. $\sigma_{\mathrm{m}}{ }^{*}$ is defined as shown in Fig.3:

$$
\sigma_{\mathrm{m}}^{*}=\frac{\mathrm{R}^{*}}{\mathrm{R}}(\boldsymbol{\sigma}-\boldsymbol{X})
$$

In this study, a new superposition of the kinematic hardening rules, which is proposed by Chen and Abel ${ }^{[23]}$, is employed. It is expressed as

$$
\mathrm{d} X=\mathrm{d} \mu_{\mathrm{s}}\left[\left(\sigma_{\mathrm{m}}^{*}-\sigma\right)+\mathrm{C}_{\mathrm{s}}(\boldsymbol{\sigma}-\boldsymbol{X})\right]
$$

This equation shows that the movement of yield surface under cyclic loading complies with the direction determined by the combination of Ziegler and Mroz hardening rules. The constant, $\mathrm{C}_{s}$, is a function of plastic strain accumulation for transient plasticity and ratchetting. Taking $\mathrm{C}_{\mathrm{s}}=0$ in equation (14), the proposed hardening rule corresponds with $\mathrm{Mroz}$ hardening rule defined in equation (12). By the consistency condition $d F=0, d \mu_{s}$ is given by

$$
\mathrm{d} \mu_{\mathrm{s}}=\frac{(\boldsymbol{\sigma}-\boldsymbol{X}) \cdot \mathrm{d} \boldsymbol{\sigma}-\mathrm{R} \cdot \mathrm{dR}}{(\sigma-\boldsymbol{X}) \cdot\left(\sigma_{\mathrm{m}}^{*}-\sigma\right)+\mathrm{C}_{\mathrm{s}} \mathrm{R}^{2}}
$$

For stable cyclic stress-strain relations, the radius of yield surface keeps the constant value, i.e., $\mathrm{dR}=0$. Therefore, the movement direction of yield surface can be expressed as

$$
\begin{aligned}
& n_{\mathrm{s}}=\frac{\delta_{\mathrm{m}} n_{\mathrm{m}}+\mathrm{C}_{\mathrm{s}} R n_{\mathrm{z}}}{\left|\delta_{\mathrm{m}} n_{\mathrm{m}}+\mathrm{C}_{\mathrm{s}} R n_{\mathrm{z}}\right|} \\
& n_{\mathrm{z}}=\frac{\sigma-X}{|\sigma-X|}, n_{\mathrm{m}}=\frac{\sigma_{\mathrm{m}}^{*}-\sigma}{\left|\sigma_{\mathrm{m}}^{*}-\sigma\right|} \\
& \delta_{\mathrm{m}}=\sqrt{\left(\sigma_{\mathrm{m}}^{*}-\sigma\right) \cdot\left(\sigma_{\mathrm{m}}^{*}-\sigma\right)}
\end{aligned}
$$

The plastic flow rule is given by equation (17) for $\mathrm{dF}=0$ and $(\sigma-\boldsymbol{X}) \cdot \mathrm{d} \sigma>0$.

$$
\mathrm{d} \varepsilon^{\mathrm{p}}=\frac{1}{\mathrm{cR}^{2}}[(\sigma-X) \cdot \mathrm{d} \sigma](\sigma-X)
$$

Table 2 Material constants used in the analysis

\begin{tabular}{l|c}
\hline Young's modulus, E & $200 \quad(\mathrm{GPa})$ \\
\hline Shear modulus, $\mathrm{G}$ & $82 \quad(\mathrm{GPa})$ \\
\hline Radius of yield surface, $\mathrm{R}$ & $200 \quad(\mathrm{MPa})$ \\
\hline Cyclic hardening coefficient, $\mathrm{K}$ & $1850 \quad(\mathrm{MPa})$ \\
\hline Cyclic hardening exponent, $\mathrm{n}$ & 0.29 \\
\hline Constant for additional hardening, $\alpha$ & 0.9 \\
\hline Material constant, $\mathrm{C}_{\mathrm{s}}$ & 1 \\
\hline
\end{tabular}

where $c$ denotes the strain hardening modulus. $d \varepsilon^{p}$ is collinear with $(\boldsymbol{\sigma}-\boldsymbol{X})$ for Mises' case. For Massing type materials, the plastic modulus of the stress-plastic strain curve (Ramberg-Osgood equation) can be expressed as $^{[22],[27]}$

$$
c=K n\left(\frac{\sigma_{e}}{K}\right)^{\frac{n-1}{n}}
$$

There are many ways to define the strain hardening modulus, c, under nonproportional loading ${ }^{[10]}$. In the model of this paper, the strain hardening modulus is assumed to be a function of the distance, $\delta_{\mathrm{s}}$, between the current stress point on the yield surface, $\sigma$, and the stress point on limit surface, $\sigma_{\mathrm{s}}^{*}$, i.e.,

$$
\delta_{\mathrm{s}}=-\boldsymbol{\sigma} \cdot \boldsymbol{n}_{\mathrm{s}}+\left[\left(\boldsymbol{\sigma} \cdot \boldsymbol{n}_{\mathrm{s}}\right)^{2}+\left(\mathrm{R}^{*}\right)^{2}-|\sigma|^{2}\right]^{\frac{1}{2}}
$$

The maximum distance is

$$
\delta_{\max }=2\left(R^{*}-R\right)
$$

Let $\mathrm{D}$ be normalized distance between $\delta_{\mathrm{s}}$ and $\delta_{\max }$.

$$
\mathrm{D}=\frac{\delta_{\max }-\delta_{\mathrm{s}}}{\delta_{\max }}
$$

The normalized D varies between zero and unity in value.

$\mathrm{n}$ and $\mathrm{K}$ which characterize the stable cyclic stress-strain must be modified to take account of the additional hardening. This study employed a simple idea,

$$
K_{N P}=\left(1+\alpha f_{N P}\right) K
$$

Therefore, the cyclic stable plastic modulus for nonproportional loadings can be expressed by 


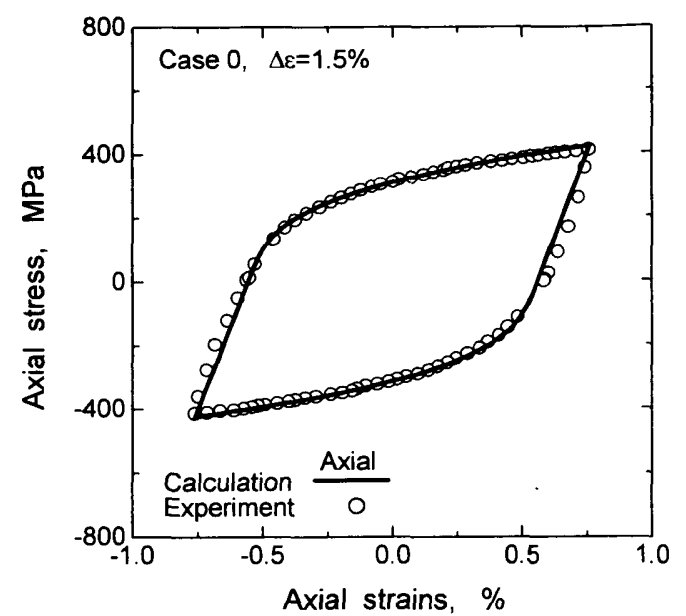

(a) Case 0

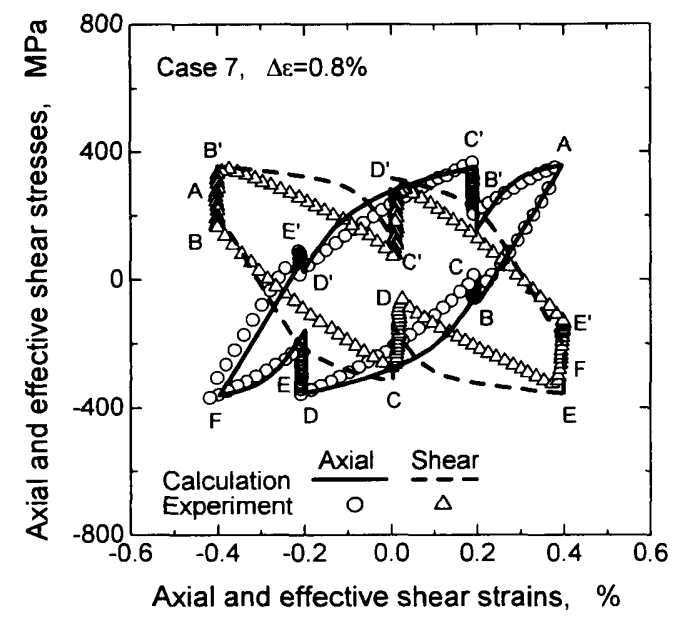

(c) Case 7

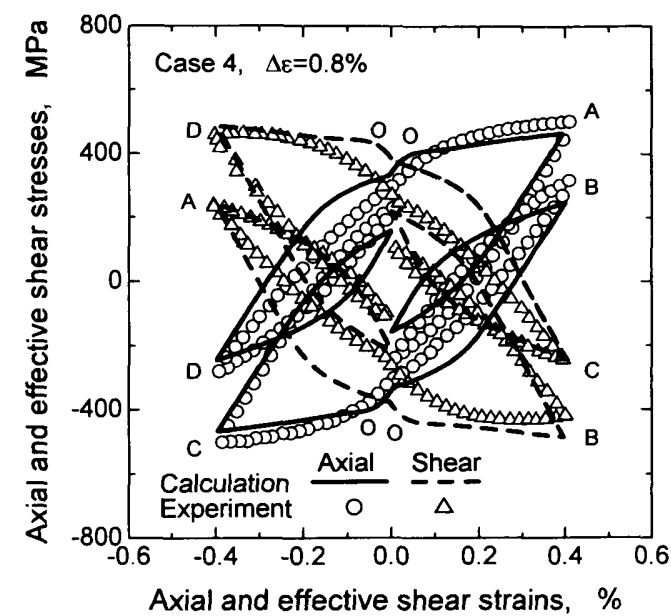

(b) Case 4

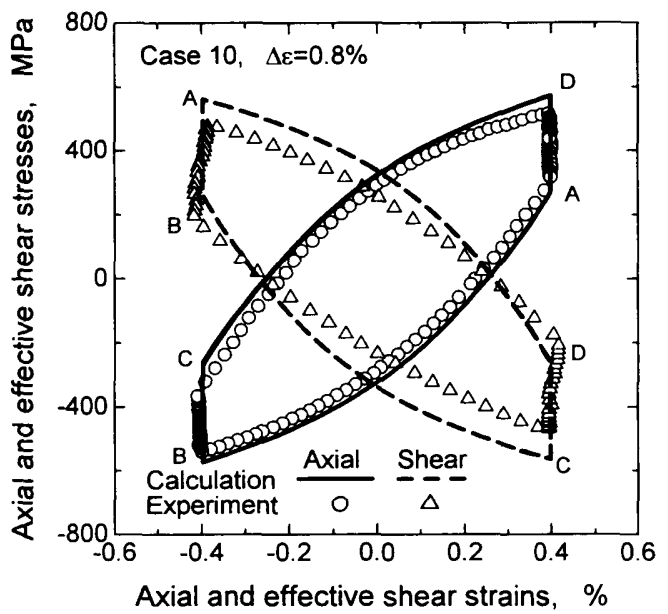

(d) Case 10

Fig.4 Stable cyclic stress-strain relationship for Case $0,4,7$ and 10

$$
c=\left(1+\alpha f_{N P}\right) \operatorname{Kn}\left(\frac{\left|2\left(R^{*}-R\right)(D-1)+R^{*}\right|}{\left(1+\alpha f_{N P}\right) K}\right)^{\frac{n-1}{n}}
$$

\section{Analytical Results and Discussion}

Material constants used for the analysis are listed in Table 2; Young's modulus is $200 \mathrm{GPa}$, shear modulus $82 \mathrm{GPa}$, radius of the yield surface $200 \mathrm{MPa}$, cyclic hardening coefficient $1850 \mathrm{MPa}$, cyclic hardening exponent 0.29 and the material constant for additional hardening $0.9^{[3]}$.

The material constant $C_{s}$, which is normally a function of plastic strain accumulated for describing the transient plasticity and ratchetting, must be determined. Under cyclic stable state, however, no or small effect of $\mathrm{C}_{\mathrm{s}}$ was observed on the peak stress in stress-strain relationship. Since the stable stress-strain relationship would be studied and $\mathrm{C}_{\mathrm{s}}$ is mainly related to the ratchetting rate ${ }^{[23]}$, $\mathrm{C}_{\mathrm{s}}$ can be taken as constant. Thus, this study takes the value of $\mathrm{C}_{s}$ as unity.

Figures 4 (a)-(d) compare the stress-strain relationship between analysis and experiment for Case 0 at $\Delta \varepsilon=1.5 \%$ and Case 4, 7 and 10 at $\Delta \varepsilon=0.8 \%$. In these figures, alphabets indicate the representative points along the strain path, Fig.2, and the stress-strain curves, Figs.4 and 5. In the uniaxial test of Case 0, Fig.4 (a), the proposed model predicts the stable cyclic hysteresis loop with satisfactory accuracy. Overall fitting between the analysis and experiment is excellent but there is a subtle difference during the unloading stage. The analytical result has a linear shape but the experimental result has a curved shape. Since the unloading stress-strain relationship must be a linear shape, the difference is 

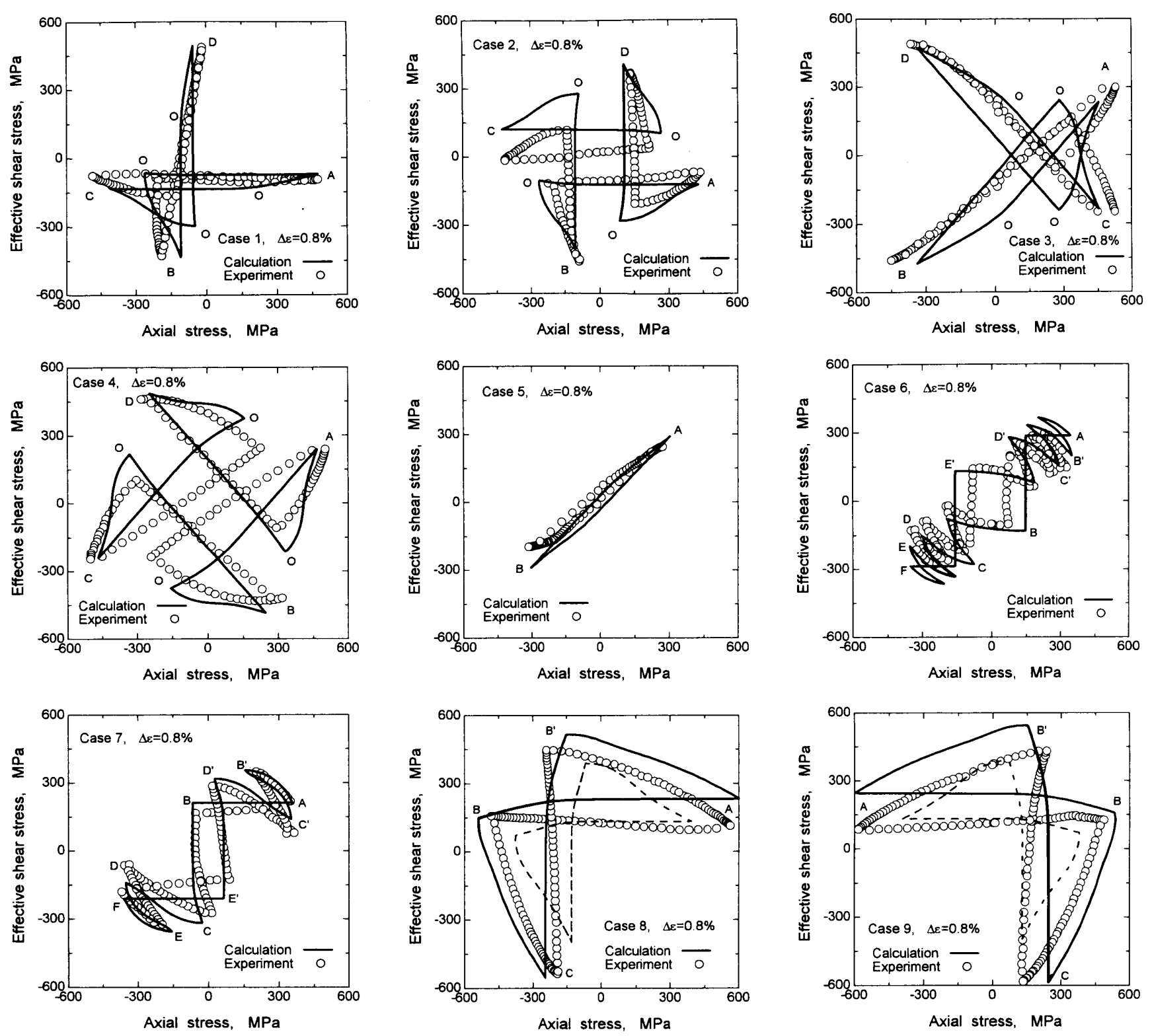

Fig. 5 Stable cyclic stress response for Case $1-13$ at $\Delta \varepsilon=0.8 \%$

presumably resulted from the inaccuracy in experiment.

In Case 4, Fig.4 (b), the model developed in this study predicts well the experimental stress response. Especially, the peak stresses of predicted at A-D agree well with these in experiment. The shape of the stress-strain curves in the analysis is somewhat different from that in experiment along the strain path, D-A and B-C in the axial component and that of A-B and C-D in the shear component. The model estimates the larger stress amplitude along these strain paths.

In Case 7, Fig.4 (c), the overall fitting of the stress-strain relationship between the prediction and experiment is good. The model has satisfactory accuracy for the axial component but there exists a relatively large difference in the shear component along the strain paths D-E and C'-B'. The peak stresses derived by the model precisely agree with those in experiment whereas the stress-strain curve shape differs between the model and experiment.

In Case 10, Fig.4 (d), the model estimates very close hysteresis loop to the experimental result in the axial component but it predicts slightly larger stress response than that in experiment for the shear component.

From the comparison of the stress response between the analysis and experiment shown in the above cases together with the other strain paths which were not 

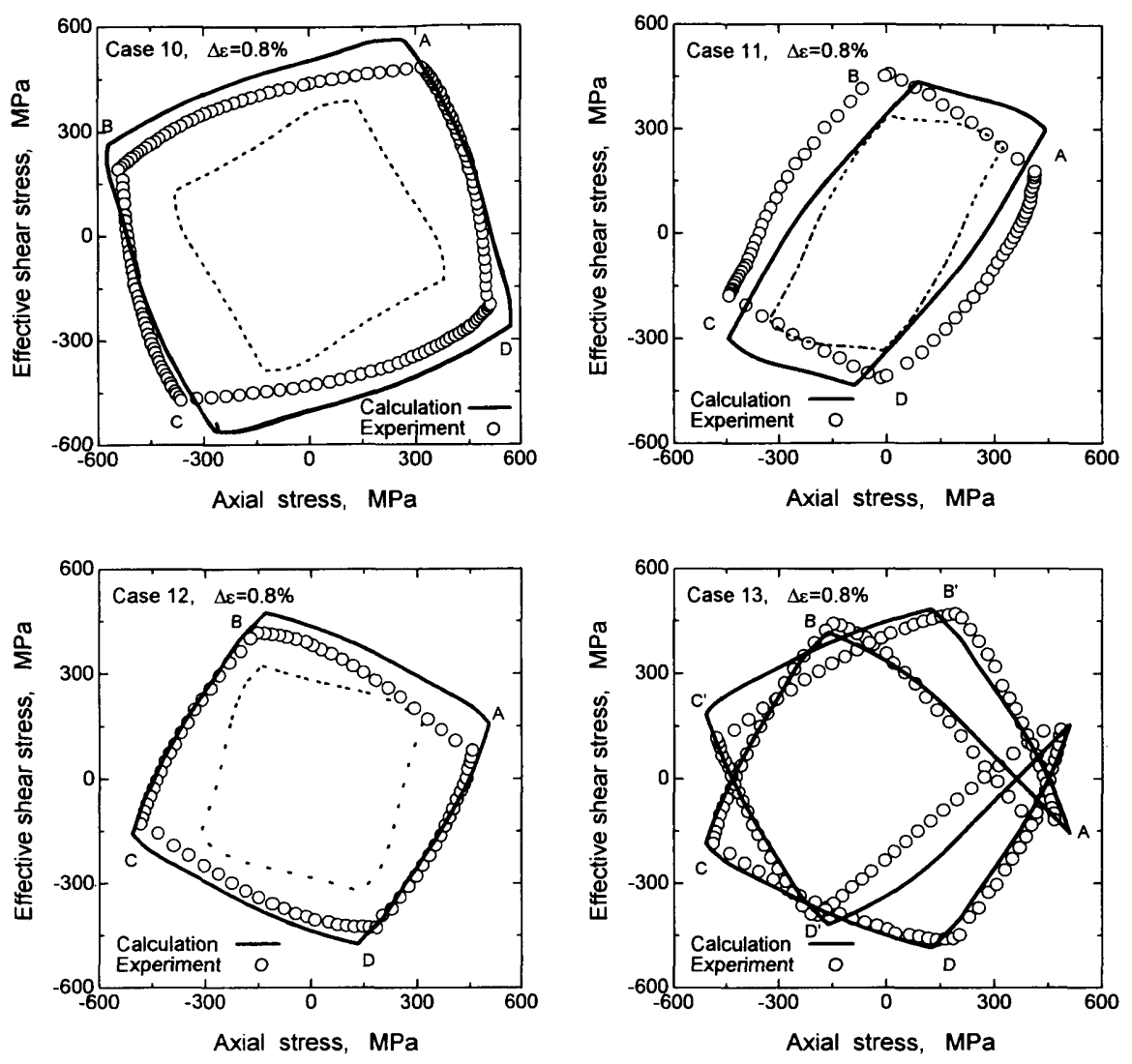

Fig.5 Stable cyclic stress response for Case $1-13$ at $\Delta \varepsilon=0.8 \%$ (Continued)

graphically presented, the overall fitting of the stress response is good between the model and experiment. The axial component in the analysis quite well agreed with that in experiment but there was small difference in the shear component. The model predicted larger stress amplitude than the experiment for shear component. One of the possible causes of the larger prediction is resulted from the stress/strain gradient into the tube wall of specimen and the short gage length. The gage part of the specimen has $1.5 \mathrm{~mm}$ in thickness and $6.4 \mathrm{~mm}$ in length. The thickness is slightly thicker and the gage length somewhat smaller for the plasticity study. However, specimens were prone to buckle under the severe nonproportional strain paths shown in Fig. 2 so that this specimen geometry was necessary. The similar trend of the data fitting in the shear components was also found in the literature ${ }^{[4]}$.

Figure 5 compares the stress response in axial-shear stress diagram at $\Delta \varepsilon=0.8 \%$. In the figures of Case $8-12$, simulated results calculated with $\alpha=0$ and $\mathrm{f}_{\mathrm{NP}}=0$ are shown by dotted lines to be examine the effect of $\alpha$ on the stress response. In cruciform strain paths, Case 1 and 2 in Fig.5, the model predicts the very close stress-strain shape and estimates the accurate peak stresses at the points of A-D. However, there are some points where the model gives the different stress response. Case 3 and 4 have the hysteresis shape rotated about 45 degrees from that in Case 1 and 2, respectively.

Case 5-7 have a similar path with the different number of principal strain direction change steps. The model gives a good agreement with the experimental results quantitatively at the respective strain path. The model follows the trend of the experimental results that the stress amplitude increases as the number of steps decreases.

For the single step and box loading of Case 8-13, the model gives an accurate prediction for a simple boxy loading of Case 10 and 12 . The model also gives a good prediction for a double box loading in Case 13. However, a small difference between the prediction and experiment exists in Case 9 for axial component at $\mathrm{C}$ and shear component at $\mathrm{A}$. This trend is also found in Case 8 which is a similar strain path as Case 9. In the loading path with phase shift, Case 11, the model predicts the larger stress amplitude along D-A and B-C. For the case of $\alpha=0$, on the other hand, there is a large 


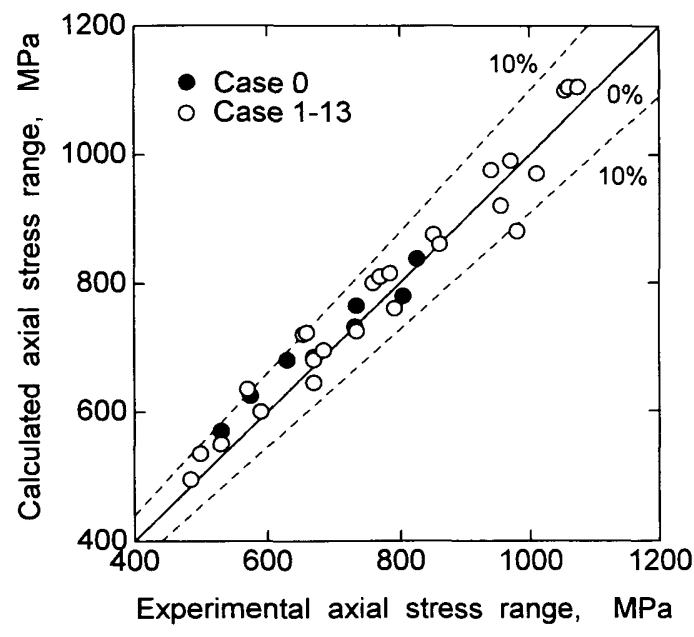

(a) Axial stress range

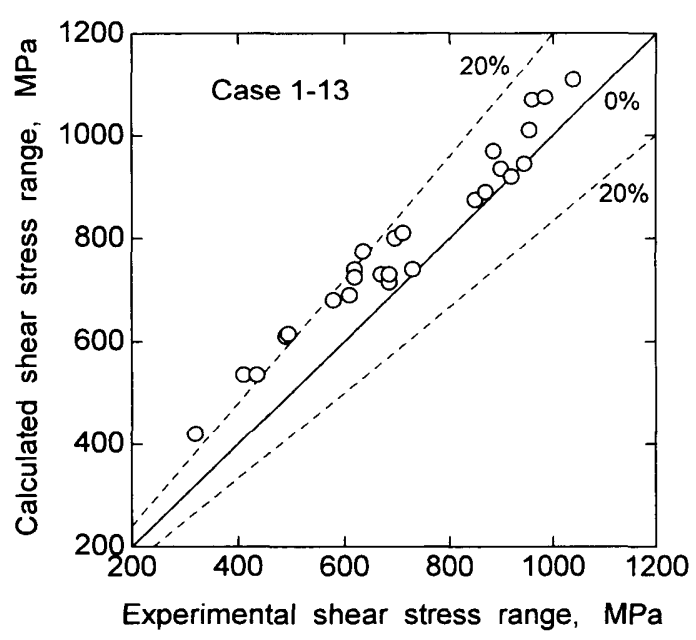

(b) Shear stress range

Fig.6 Comparison of axial and shear stress ranges between the analysis and experiment

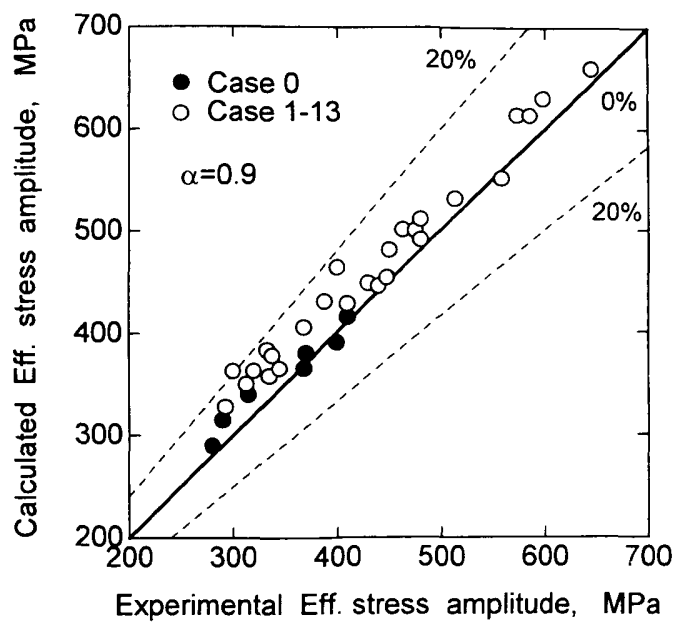

(a) $\alpha=0.9$

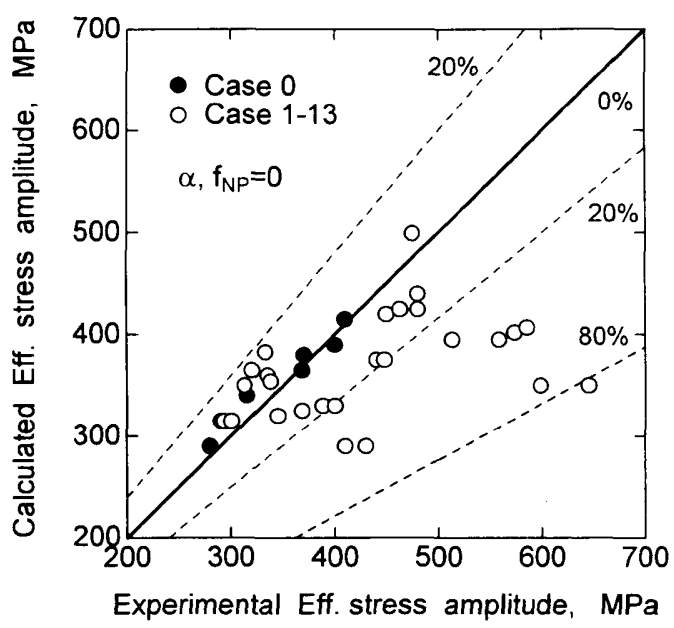

(b) $\alpha, \mathrm{f}_{\mathrm{NP}}=0$

Fig.7 Comparison of calculated and experimental effective stress amplitudes difference in stress between the analysis and experiment shown by the dotted lines for Case 8-12. These figures clearly show that the large contribution of $\alpha$ and $f_{N P}$ exists in the prediction of stable cyclic stress response under nonproportional loading.

In conclusion, the model evaluates a relatively accurate stress response under nonproportional loading except a few cases. The stress amplitude calculated by the proposed model agrees well with the experimental results for a wide variety of strain paths whereas a small difference partly exists. The overall fitting is concluded to be satisfactory.

Figure 6 shows the comparison of stress range between analysis and experiment. The axial stresses calculated by the model are within a factor of $10 \%$ scatter band in comparison with experimental data in all the tests, Fig.6 (a). The scatter of data is slightly larger in shear component and the scatter band is a factor of 1.2, Fig.6 (b). The larger scatter in the shear component may be resulted from the geometry of the specimen.

Figure 7 (a) is a replot of Fig.6 and shows the comparison of the equivalent stress between analysis and experiment. The figure shows that the simulation estimates the equivalent peak stress within a factor of 1.2. In Fig.7 (b) where the calculation was carried out under $\alpha=0$ and $\mathrm{f}_{\mathrm{NP}}=0$, some of the data under nonproportional loading are obviously underestimated by more than a factor of 1.2. The larger scatter of the data can be seen under the larger $\mathrm{f}_{\mathrm{NP}}$ 's tests, such as Case 10 and 12 . The maximum scatter was almost a factor of 2 which corresponds with the value of $\alpha$ for Type 304 stainless steel used in this study. A contribution of $\left(1+\alpha f_{N P}\right)$ to 
the simulation is very large and the simple model proposed has enough precision to calculate cyclic stable stress-strain relationship along widely ranged nonproportional straining.

\section{Conclusions}

1. This study proposed a simple two-surface plasticity model which has only seven material constants. This model is based on a superposed Mroz's and Ziegler's kinematic hardening rules for describing the stress and strain relationship under nonproportional strain loadings.

2. The term of $\left(1+\alpha f_{N P}\right)$ which was proposed for the nonproportional low cycle fatigue life prediction was successfully incorporated into the plasticity model to describe the additional hardening quantitatively. $\alpha$ and $\mathrm{f}_{\mathrm{NP}}$ are the constants related to the material dependency of additional hardening and the nonproportional factor.

3. The proposed model simulated the stable cyclic stress-strain response under 14 types of proportional and nonproportional strain histories with a satisfactory accuracy. The model also predicts the stress amplitude of all the tests within a $20 \%$ scatter band.

\section{References}

[1] D.L. McDowell, Proc. Int. Conf. on Constitutive Laws for Engng. Mater., Tucson, AZ, (Desai and Gallagher, eds.), 125 (1983).

[2] S.H. Doong, D.F Socie and I.M Robertson, ASME Journal of Engineering Materials and Technology, 112,456 (1990).

[3] T. Itoh, M. Sakane, M. Ohnami and D.F. Socie, ASME Journal of Engineering Materials and Technology, 117, 285 (1995).

[4] D.F. Socie, Multiaxial Fatigue Damage Models, ASME Journal of Engineering Materials and Technology, 109, 293 (1987).

[5] E. Krempl and H. Lu, Mechanics of Materials, 2, 183 (1983).

[6] T. Itoh, M. Sakane, M. Ohnami and K. Ameyama, J. Soc. Mat. Sci., Japan, 41-468, 1361 (1992).

[7] T. Itoh, M. Sakane, M. Ohnami and K. Ameyama, Proceedings of MECAMAT'92, International Seminar on Multiaxial Plasticity (Cachan, France), 43 (1992).

[8] T. Itoh, M. Sakane M. Ohnami and D.F. Socie, Proceedings of 5th International Conference on Bi-
axial/Multiaxial Fatigue and Fracture (Cracow, Poland), I, 173 (1997).

[9] D.L. McDowell, ASME Journal of Applied Mechanics, $\underline{52}, 298$ (1985).

[10] D.L. McDowell, ASME Journal of Applied Mechanics, $\underline{52}, 303$ (1985).

[11] E. Krempl, and H. Lu, ASME Journal of Engineering Materials and Technology, 106, 376 (1984).

[12] A. Benallal and D. Marquis, ASME Journal of Engineering Materials and Technology, 109, 326 (1987).

[13] D.L. McDowell, Nonproportional Cyclic Plasticity, ASME Journal of Applied Mechanics, 54, 323 (1987).

[14] J.L. Chaboche and D. Nouailhas, ASME Journal of Engineering Materials and Technology, 111, 384 (1989).

[15] J.L. Chaboche and D. Nouailhas, ASME Journal of Engineering Materials and Technology, 111, 409 (1989).

[16] S.H. Doong, and D.F. Socie, ASME Journal of Engineering Materials and Technology, 113, 23 (1991).

[17] N. Ohno and J.D. Wang, Trans. SMiRT 11 (Tokyo), L, 481 (1991).

[18] R.D. Krieg, ASME Journal of Applied Mechanics, $\underline{28}, 641$ (1975).

[19] Y.F. Dafalias and E.P. Popov, ASME Journal of Applied Mechanics, $\underline{43}, 645$ (1976).

[20] H.S. Lamba and O.M. Sidebottom, ASME Journal Engineering Materials and Technology, 100, 104 (1987).

[21] N.T. Tseng and G.C. Lee, ASCE Journal of Engineering Mechanics, $\underline{109}, 795$ (1987).

[22] F. Ellyin and Z. Xia, J. Mech. Phys. Solids, 37, 71 (1989).

[23] X. Chen and A. Abel, ACTA Mechanics Sinica (English Series), 12-4, 368 (1996).

[24] S. Kida, T. Itoh, M. Sakane, M. Ohnami and D.F. Socie, 20-10, 1375 (1997).

[25] H. Ziegler, Quarterly of Applied Mechanics, 7, 55 (1959).

[26] Z. Mroz, Acta. Mechanica, 7, 199 (1969).

[27] Y.L. Lee, Y.J. Chiang and H.H. Wong., ASME Journal Engineering Materials and Technology, 117, 33 (1995). 